minimum concentration for fibre formation and $\gamma$ is a kinetic coefficient. Since red blood cells remain for about $1 \mathrm{~s}$ in capillaries, the delay time is the critical factor in whether or not a cell sickles and since the order is extremely high (about 40th), small changes in the parameters contributing to $S$ can greatly alter the delay time. For example, the analysis indicates that the delay time in sickle cell trait is about 25,000 times longer than for sickle cell disease. Thus individuals with the trait are essentially free of symptoms and even a small increase in the delay time, as produced by some therapeutic agent, could greatly ameliorate the clinical course of the disease.

The sickling process is also complicated by factors related to the cell membrane. This point was emphasised in the presentation of M. J. Messer (University of California, San Francisco) who discussed experiments on cell sickling monitored by filterability, light microscopy and electron microscopy. When sickling is initiated by rapid deoxygenation, cell rigidity is detected before intracellular fibres or shape changes in the cells appear.

In summary, while considerable progress is being made in sickle cell disease, the complexities of a highly cooperative anisotropic assembly reaction in the confines of a cell membrane are likely to hold many surprises. The latest findings as reported at the Dallas symposium should soon be available to interested readers in detail, since the organisers promise prompt publication of the proceedings.

\section{Calculating radiation risks}

from a Correspondent

A meeting organised by the Society for Radiological Protection was held in London on February 3.

What risks are you prepared to accept and what risks does your society seem prepared to accept? These were among the questions tackled by W. D. Rowe (US Environmental Protection Agency). The problem of assessing the biological effects of exposing large populations to small amounts of ionising radiation is currently a live issue in radiological protection circles. The man rem is the unit for the quantity "collective dose equivalent' used in discussions of this question and the theme of the Society's meeting was the application of the man rem concept. Rowe pointed out that a central issue was the association of man rems with risk. The risks were to be balanced against the benefit which the population derived from the practices giving rise to the exposure. There were different types of risk, those arising from the planned releases of radioactive materials and those resulting from accidental situations. Rowe went on to analyse the factors important in the evaluation of risks and accepted that value judgments were an essential part of this procedure. The Environmental Protection Agency had, for example, used collective dose for regulatory purposes. They had set standards and determined the cost of carrying these out by using what Rowe called "operational value judgments" to determine how much money should be spent on "health effect avoidance". He felt that such value judgments were useful in this context for although subjective they did lead to decisions and action. They could be challenged and discussed and had been found to be helpful for that reason.

Any consideration of collective dose must deal with the significance of the large numbers of man rems arising from very small doses to very large numbers of people. P. M. Bryant (National Radiological Protection Board) had some forthright suggestions to offer. She felt that as we were all exposed to natural background radiation and as its level varied, for example, with geographical location, for the purpose of determining collective dose it was not reasonable to integrate doses below a level which fell well within the variation of natural background. She considered that it should be possible to define processes giving rise to exposures of the public in terms of "practices" which were of such a nature that significant numbers of individuals exposed in the overlapping fringe areas of several practices did not unwittingly receive more than the standard deviation of the background, that is, 10 millirems per year. A practice so defined might be, for example, all the long lived nuclides discharged during the 30 years of the life of a nuclear power plant. Bryant thought that if a reduction in the 10 millirem was made by one order of magnitude to allow for the number of practices going on at any one time and by another order of magnitude to allow for considerations of the future, then the resulting 0.1 mrem per year could be used as a cut-off. Below this the doses would be deemed to be insignificant and would not be used in any integration to obtain collective dose equivalent where such integration is intended for making choices between one practice and another. It seemed to her that this cut-off level would assist in realistic cost/benefit analysis although she admitted that if her concept of "collective dose from a practice" were used the definition of the practice might sometimes present difficulties.

During his discussion of two methods of considering radioactive releases arising from the operation of nuclearpowered electricity generating stations, R. H. Clarke (CEGB Berkeley Nuclear Laboratories) commented that the Canadians neglected doses below $1 \%$ of the dose at the site boundary and the Americans also employed a cut-off by integrating only the doses received within 50 miles of the site. Releases could be considered in terms of the doses given to a hypothetical critical group of the public located at the site boundary close to the release point. If the doses to this group were kept within the limits recommended by international authorities, then it followed that the doses received by the rest of the population would also be considered acceptable. This in fact was the approach used at present by the Central Electricity Board, but Clarke pointed out that it was possible for the doses to the critical group to remain within the arbitrary limits, yet, by varying stack heights, the distance from the release point to the site boundary and the distribution of the population around the site, the collective dose equivalent from similar releases of xenon-133 could vary by two orders of magnitude. This indicated a weakness of the critical group approach and in future although the doses to the most exposed individuals would remain important, some kind of limitation on the population collective dose around the site might be a more realistic parameter for the design engineer to aim at.

R. H. Mole (MRC Radiobiology Unit, Harwell) speaking in his private capacity, said it was important to distinguish between the validity of using man rems for thinking about exposures and for adding units of risk, and the validity of converting man rems into cases of detriment or hurt in some sense. Alternative hypotheses concerning the slope of the dose response relationship had to be considered. $\mathrm{He}$ was personally inclined to accept the linear hypothesis and was therefore critical of those who proposed a cut-off. It seemed to him that there was no adequate scientific reason for rejecting linearity and he suspected that there must be some "cultural" reason for distrusting it. Perhaps people were uneasy about calculating risks on the basis of a hypothesis which could not be demonstrated to be true.

The meeting was concluded by Mole pleading for those who published estimates of collective dose to set out every step of their calculations and in particular to state the range of uncertainty of the final number. A salutory exercise, no doubt! 